\title{
SORVETE SABOR ABACAXI DE BAIXA CALORIA: ANÁLISE DE DOMINÂNCIA TEMPORAL DE SENSAÇÕES E ESTUDOS COM CONSUMIDORES
}

\section{Beatriz Rovere*, Helena M. A. Bolini.}

\section{Resumo}

O objetivo do presente estudo foi elaborar seis diferentes formulações de sorvete de abacaxi natural sendo um adoçado com sacarose e cinco com edulcorantes (estévia RebA97\%, estévia RebA92\%, sucralose, aspartame e xilitol, em mesma doçura equivalente) e compará-las em relação à aceitação e à dominância temporal das sensações (TDS), bem como gerar informações científicas acerca da percepção dinâmica de gostos e sabores para o produto em questão. Os dados obtidos foram analisados estatisticamente, aplicando-se análises de variância (ANOVA), testes de médias de Tukey e análise estatística multivariada de Mapa Interno de Preferência.

\section{Palavras-chave:}

sorvete de abacaxi, edulcorante, análise sensorial

\section{Introdução}

O sorvete é um produto bastante consumido pela população mundial, sendo denominado pela RDC no 266 da Agência Nacional de Vigilância Sanitária ${ }^{1}$ como "gelado comestível" e caracterizado por ser obtido a partir de uma emulsão de gorduras e proteínas ou pela mistura de água e açúcares.

Atualmente, como há uma busca por dietas mais saudáveis e com redução do consumo de açúcares, o estudo sensorial tornou-se um importante instrumento científico capaz de avaliar a aceitação de produtos no qual há substituição de sacarose por edulcorantes, além de gerar dados sobre a percepção dinâmica de sabores e gostos ao decorrer do tempo de interação com o alimento.

\section{Resultados e Discussão}

Para a formulação dos sorvetes sabor abacaxi utilizou-se inicialmente a fruta liofilizada em pó, uma vez que este processo de desidratação proporciona diversos benefícios como a preservação dos nutrientes e do sabor do produto. No entanto, observou-se na análise de aceitação que houve um desenvolvimento excessivo de sabor amargo, comprometendo o produto.

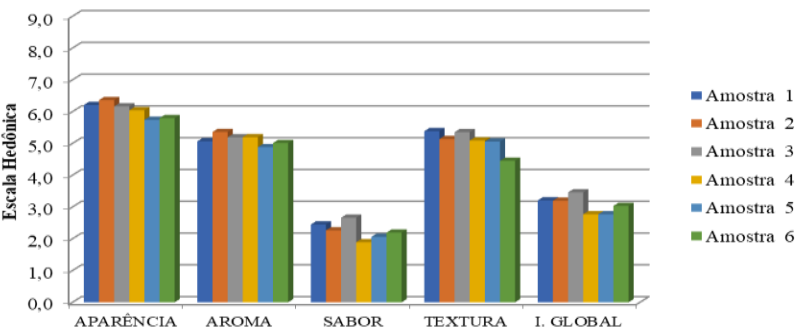

Figura 1. Médias de aceitação das amostras de sorvete com abacaxi liofilizado.

Para corrigir o problema e possibilitar a análise desejada, formularam-se novos sorvetes utilizando polpa de abacaxi. Foi realizada uma nova análise de aceitação, por meio de um teste afetivo com escala hedônica não estruturada de $9 \mathrm{~cm}$ com um grupo de consumidores representativos do público alvo, bem como a análise TDS (Temporal Dominance of Sensations).

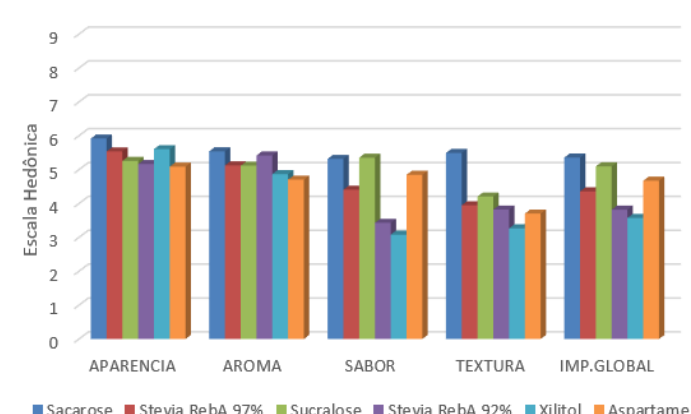

Figura 2. Médias de aceitação das amostras de sorvete com polpa de abacaxi.

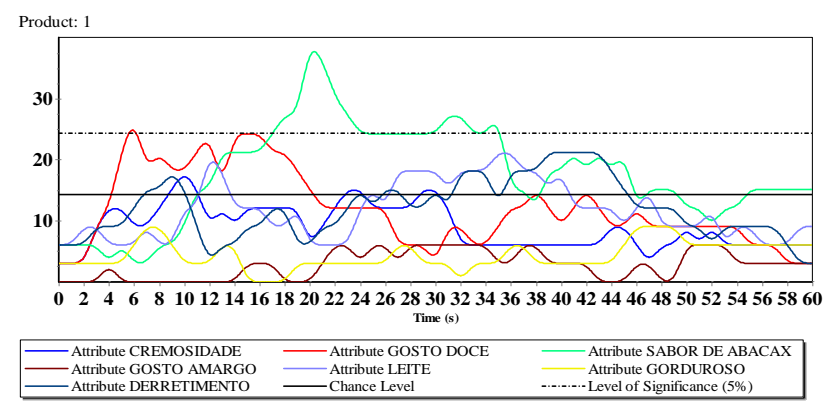

Figura 3. Painel de dominância de atributos para a amostra com sacarose para análise TDS.

\section{Conclusões}

Observou-se que as amostras com substituição por sucralose e aspartame apresentaram médias de aceitação bastante próximas a da amostra com sacarose e em ambas houve dominância do gosto doce $(>30 \%)$ pela análise TDS, além da dominância de sabor de abacaxi na amostra com sucralose.

\section{Agradecimentos}

Gostaria de agradecer minha orientadora Profa. Dra. Helena M. A. Bolini e todos que trabalham no Laboratório de Ciência Sensorial e Estudo de Consumidor (FEA), o CNPq e a Liomeal, empresa que contribuiu com a doação do abacaxi liofilizado.

\footnotetext{
${ }^{1}$ Agência Nacional de Vigilância Sanitária (ANVISA). Resolução da Diretoria Colegiada (RDC) no 266, de 22 de setembro de 2005.
} 